\title{
Genome size and maturity group in Glycine $\max$ (soybean)
}

\author{
JOHANN GREILHUBER* \& RENATE OBERMAYER \\ Institute of Botany, University of Vienna, Rennweg 14, A-1030 Vienna, Austria
}

\begin{abstract}
Recent literature data indicate a 1.15-fold difference in genome size between certain cultivars of soybean and a positive correlation of genome size and maturity group. The present analysis aims at a reinvestigation of these cultivars using DAPI and ethidium bromide flow cytometry and Feulgen densitometry. No reproducible genome size differences were found between these cultivars with either technique, and correlation with maturity group was not confirmed. The previously claimed statistical significance of such a correlation was found to result from only one exceedingly low DNA value of an early maturing cultivar, which, according to our data, is not different from the others.
\end{abstract}

Keywords: Feulgen densitometry, flow cytometry, genome size, Glycine max, maturity group.

\section{Introduction}

The variation of genome size below the taxonomic level of the species and, in particular, the correlation of genome size with ecologically relevant parameters of the environment and the organism is of increasing interest in the contemporary literature (e.g. Rayburn et al., 1985; Bennett, 1985, 1987; Price, 1988; Rayburn, 1990; Rayburn \& Auger, 1990; Graham et al., 1994; Bennett \& Leitch, 1995). The soybean, Glycine max, is one of the species in which, as in maize (Rayburn et al., 1985), lower genome sizes have been found in cultivars adapted to higher latitudes where the vegetation period is shorter (Graham et al., 1994). This interesting correlation and the high genome size variation in Glycine max generally, which can be seen from the literature (Bennett, 1985), prompted us to reinvestigate the cultivars studied by Graham et al. (1994). The techniques applied were DAPI and ethidium bromide flow cytometry and Feulgen densitometry.

\section{Materials and methods}

Nineteen of the 20 cultivars of Glycine max investigated by Graham et al. (1994) were obtained from the USDA Soybean Germplasm Collection, University of Illinois, Department of Agronomy, Urbana, U.S.A. Four of these lines were also obtained via the

\footnotetext{
${ }^{*}$ Correspondence. E-mail: irmgard.greilhuber@univie.ac.at
}

Institute of Plant Cultivation and Breeding, University of Agriculture, Vienna, Austria. Pisum sativum 'Kleine Rheinländerin' of commercial origin was used as internal standard.

The seeds were germinated on plates, and primary and some side roots were taken for densitometric analysis. Young leaves were used for flow cytometry. Seedlings of Glycine max were kept for some time on hydroculture.

The flow cytometer was a Partec CA II equipped with a mercury lamp. The flow cytometric procedure with DAPI followed Baranyi \& Greilhuber (1995) and with ethidium bromide (EB) Baranyi \& Greilhuber (1996). Propidium iodide (PI) was used in the same way as EB, but with Omega filters 535DF35 (excitation), 575DRLPO2 (beam splitter) and a long pass 590 barrier filter; a heat protection filter KG1 was used.

As a methodological principle, for comparative measurements in flow cytometry, every nuclear isolation was jointly carried out for one individual of the test material and one of the internal standard, Pisum sativum 'Kleine Rheinländerin', thereby ensuring identical conditions for both during isolation and further processing. Zea mays, which was used as external standard by Graham et al. (1994), could not be used with EB or PI because its $G_{1}$ peak coincides with the $\mathrm{G}_{2}$ peak of soybean. However, there was no overlap with DAPI, and Zea mays 'Sundance' was used as standard in a test involving the most different cultivars in the study by Graham et al. 
(1994). Hedera helix was used for the same purpose as standard in a test with PI simply because it has a suitable genome size difference from Glycine max.

Feulgen densitometry followed Greilhuber \& Ebert (1994); details are explained in Tables 1 and 2. Because of the low genome size in soybean, metaphases in side view were measured to obtain a reasonable amount of absorbance. When Pisum sativum 'Kleine Rheinländerin' was included for picogram calculation, telophase nuclei were measured because they were of similar average absorbance per area unit to Glycine max metaphases.

Single classification analysis of variance, Scheffé test and correlation analysis were performed with the sPSS for Windows 6.0 package (SPSS, Chicago, IL, U.S.A.) and nested analysis of variance with the NESTAN routine of the BIOM-pc Version 2.1. package (Rohlf, 1992).

Table 1 Genome size comparison in 19 cultivars of Glycine max with reference to maturity group assignment, and comparison with the data of Graham et al. (1994)

\begin{tabular}{|c|c|c|c|c|c|c|c|c|c|c|}
\hline \multirow[b]{2}{*}{ Cultivar } & \multirow{2}{*}{$\begin{array}{l}\text { Maturity } \\
\text { group* }\end{array}$} & \multicolumn{3}{|c|}{$\begin{array}{c}\text { Data of Graham et al. } \\
(1994) \dagger\end{array}$} & \multicolumn{2}{|c|}{ DAPI $\ddagger$} & \multicolumn{2}{|c|}{$\mathrm{EB} \S$} & \multicolumn{2}{|c|}{ Feulgen } \\
\hline & & Rank & Mean & $\mathrm{SD}$ & Mean & SDtt & Mean & SD+† & Mean & SD \\
\hline BSR 201 & II & 1 & 103.37 & 0.12 & 100.22 & 0.53 & 99.29 & 0.70 & 99.09 & 4.12 \\
\hline Hardee & VIII & 2 & 102.65 & 1.26 & 100.90 & 1.07 & 99.98 & 1.26 & 101.34 & 4.38 \\
\hline Jupiter & IX & 3 & 101.34 & 1.23 & 100.09 & 0.88 & 99.95 & 2.41 & 100.73 & 4.76 \\
\hline Jack & II & 4 & 101.21 & 1.50 & 99.26 & 1.12 & 99.62 & 0.63 & 99.91 & 3.64 \\
\hline Hartwig & V & 5 & 101.11 & 0.85 & 100.34 & 0.74 & 100.10 & 2.19 & 98.81 & 4.14 \\
\hline Bell & I & 6 & 100.97 & 1.63 & 99.65 & 0.93 & 100.24 & 0.89 & 101.97 & 4.00 \\
\hline Aojia & III & 7 & 99.84 & 2.39 & - & - & - & - & - & - \\
\hline Resnik & III & 8 & 99.66 & 2.08 & 101.04 & 0.71 & 99.91 & 1.58 & 100.59 & 4.36 \\
\hline Gnome 85 & II & 9 & 99.22 & 1.15 & 100.30 & 0.64 & $95.63^{* *}$ & 2.58 & 101.35 & 4.65 \\
\hline Maple Ridge & $00(000)$ & 10 & 98.45 & 1.27 & 100.01 & 0.94 & 100.52 & 1.55 & 100.17 & 4.66 \\
\hline Sioux & 000 & 11 & 98.08 & 1.59 & 99.39 & 1.32 & 100.42 & 1.41 & 102.31 & 3.83 \\
\hline Agassiz & $00(0)$ & 12 & 97.99 & 0.73 & 99.96 & 1.13 & 100.61 & 1.67 & 98.27 & 3.62 \\
\hline Crockett & VIII (VII) & 13 & 97.47 & 1.19 & 100.23 & 0.70 & 99.81 & 1.05 & 98.83 & 3.35 \\
\hline Hood & VI & 14 & 97.27 & 1.75 & $101.68^{* *}$ & 1.25 & 102.31 & 2.15 & 99.43 & 4.26 \\
\hline Pando & 000 & 15 & 97.11 & 1.06 & 100.22 & 0.69 & $103.17^{* *}$ & 3.25 & 100.39 & 3.56 \\
\hline Dawson & 0 & 16 & 96.87 & 1.60 & 99.21 & 1.00 & 97.92 & 1.49 & 97.61 & 4.51 \\
\hline McCall & 00 & 17 & 96.06 & 0.60 & 100.56 & 0.93 & 101.66 & 1.49 & 99.88 & 4.91 \\
\hline Corsoy 79 & II & 18 & 95.99 & 0.59 & 98.49 & 1.76 & 99.18 & 1.31 & 100.02 & 4.16 \\
\hline Amsoy & II & 19 & 95.51 & 1.33 & 98.69 & 0.69 & 100.06 & 1.61 & 99.80 & 3.86 \\
\hline Maple Presto & 000 & 20 & 90.00 & 1.21 & 99.90 & 1.58 & 99.41 & 0.76 & 99.51 & 3.88 \\
\hline
\end{tabular}

*USDA assignment, deviating group designation in Graham et al. (1994) in brackets. No correlation with our data obtained with DAPI $(r=0.3397, P=0.155), \mathrm{EB}(r=-0.1210, P=0.622)$ or Feulgen $(r=0.0107, P=0.965)$ or with the mean of these three techniques $(r=0.0379, P=0.877)$.

†DNA content data relative to $G$. max 'Burlison' (set to 100.00), which was used as external standard. No significant correlation exists with our data obtained with DAPI $(r=0.2438, P=0.314)$, EB $(r=-0.0970, P=0.693)$, Feulgen $(r=0.2434, P=0.315)$, and the mean of these three techniques $(r=0.1438, P=0.557)$.

$\$$ Data normalized to the grand mean set to 100.00 ; no significant correlation with maturity groups $(r=0.3397, P=0.155)$, EB data $(r=0.3076, P=0.200)$ and Feulgen data $(r=0.0460, P=0.852)$. The averaged soybean-pea ratio was 0.2974 , $\mathrm{SD}=0.0037$ ( $n=171$, three runs per individual, three individuals per cultivar).

$\S$ Data normalized to the grand mean set to 100.00 ; no significant correlation with maturity groups $(r=-0.1210$, $P=0.622)$, DAPI data $(r=0.3076, P=0.200)$ and Feulgen data $(r=0.0046, P=0.985)$. The averaged soybean-pea ratio was $0.2566, \mathrm{SD}=0.0057$ ( $n=171$, three runs per individual, three individuals per cultivar).

INineteen secondary root tip meristems, one per cultivar, were processed simultaneously, and all values normalized taking the mean as 100.00; five such sets using different individuals were combined in this column, its grand mean is 100.00 ; SD refers to $n=50$. No significant correlation with maturity groups $(r=0.0107, P=0.965)$, EB data $(r=0.0046, P=0.985)$ and DAPI data $(r=0.0460, P=0.852)$. Each set also included one secondary root tip of Pisum sativum, of which 10 nuclei
were measured; the averaged soybean-pea ratio was 0.2551 .

*** Cultivars contributing to heterogeneity at $P<0.05$ according to the Scheffé test.

$\dagger+$ Number of runs $n=9$ (three runs per individual, three individuals per cultivar). 


\section{Results}

Ethidium bromide flow cytometry in 19 Glycine max cultivars resulted in a maximum difference of 1.079-fold between cultivars, which was significant at the 5 per cent level on nested analysis of variance (Table 1). Most of these differences were not significant on the Scheffé test. The significance results from the two extreme values only, of 'Gnome' and 'Pando', which rank intermediate in Graham et al. (1994). Reanalysis of these cultivars with PI (three individuals per cultivar, three runs per individual) showed that they are not actually different $\left(F_{1,4}=2.5202\right)$, nor were individuals within cultivars $\left(F_{4,12}=1.3111\right)$. That Glycine $\max$ 'BSR 201' and 'Maple Presto', the cultivars showing the maximum difference of 14 per cent in Graham et al. (1994), are very similar is shown in Fig. 1, in which juvenile leaves of a Hedera helix plant were used as reference. On average, the genome size of Glycine max was 0.2566-fold that of Pisum sativum 'Kleine Rheinländerin', which amounts to $1.134 \mathrm{pg}(1 \mathrm{C})$, if the $1 \mathrm{C}$ value of Pisum sativum is taken as 4.42 pg (Greilhuber \& Ebert, 1994). (The resulting $1 \mathrm{C}$ value for Hedera helix of $1.44 \mathrm{pg}$ fits very well with the value of $1.48 \mathrm{pg}$ published by König et al., 1987.) Our value for Glycine max is very similar to the values of Hammatt et al. (1991) of $1.175 \mathrm{pg}$ (1C) for Glycine max and $1.14 \mathrm{pg}$ (1C) for $G$. soja, its wild progenitor.

The same cultivars were also analysed with DAPI (Ulrich \& Ulrich, 1986), an AT-specific fluorochrome of high fluorescence yield, which shows less dependence on the chromatin condensation state than EB and PI (Doležel, 1991; Doležel et al., 1992). The maximum difference between cultivars was 1.032-fold, which was again significant at the 5 per cent level (Table 1). This significance was only caused by the highest value, which ranks intermediate in Graham et al. (1994) and relatively high in our $\mathrm{EB}$ analysis (Table 1). A reanalysis of the cultivars ranking highest and lowest in Graham et al. (1994), i.e. 'BSR 201' and 'Maple Presto', with DAPI and Zea mays 'Sundance' as standard, revealed a difference of only 1.0095 -fold, which is not significant. Combined runs of both cultivars resulted in unimodal and symmetric $G_{1}$ peaks at a coefficient of variation $(\mathrm{CV})$ of 1.9 per cent, again demonstrating the absence of reasonable differences between these lines.

Four tests were carried out with Feulgen densitometry, three of these including Pisum sativum for comparison. One comprehensive test involved all 19 cultivars, five individuals per cultivar and one secondary root tip meristem per individual (Table 1).
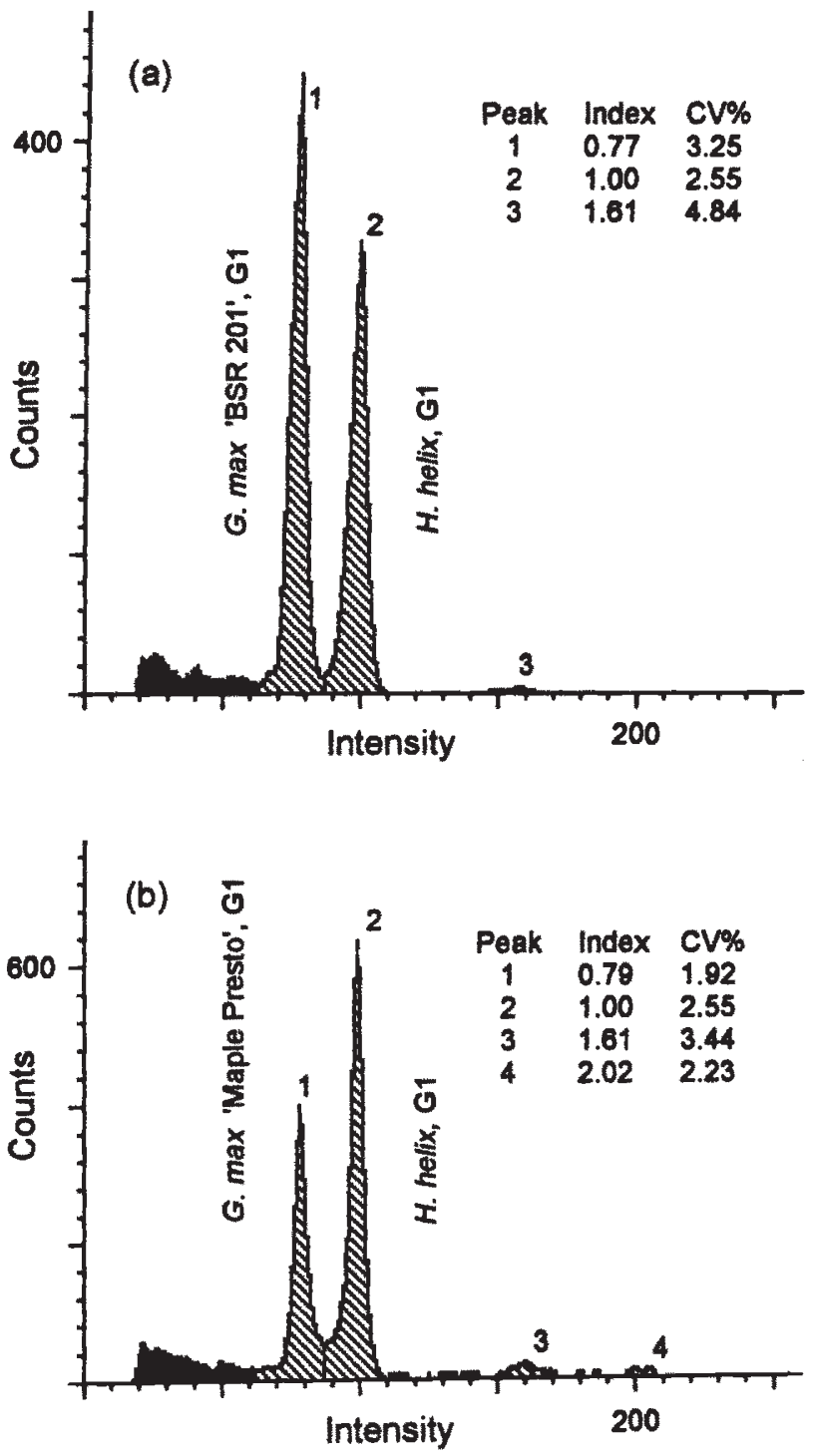

Fig. 1 Simultaneous propidium iodide flow cytograms of Glycine max cultivars and Hedera helix (as standard), demonstrating genome size constancy in the Glycine max strains (a) 'BSR 201' and (b) 'Maple Presto'.

The maximum difference was 1.048 -fold, which was nonsignificant on nested analysis of variance. Another test (Table 2) involved 'Maple Ridge', 'Pando', 'McCall' and 'Maple Presto', showing up to a 1.094-fold difference according to Graham et al. (1994). The maximum difference was 1.01-fold, which was clearly nonsignificant. Two further tests (Table 2) were carried out involving the two cultivars ranking highest and the two ranking lowest in the study of Graham et al. (1994). One test was made with formaldehyde as fixative (see Greilhuber, 1986, 1987; and Greilhuber \& Ebert, 1994 for the rationale). Again, no difference between the culti- 
Table 2 Feulgen densitometric comparison in primary root tip meristems of Glycine max cultivars (three separate tests, a-c, data of each normalized to 100.00 for its grand mean)

\begin{tabular}{cclrcc}
\hline Test & Rank & Cultivar & Mean & SD & $n$ \\
\hline a† & 10 & Maple Ridge & 100.29 & 2.68 & 30 \\
& 15 & Pando & 99.75 & 3.37 & 30 \\
& 17 & McCall & 100.48 & 2.42 & 30 \\
& 20 & Maple Presto & 99.48 & 2.66 & 30 \\
bł & 1 & BSR 201 & 99.27 & 3.75 & 50 \\
& 2 & Hardee & 99.66 & 3.83 & 50 \\
& 19 & Amsoy & 100.51 & 3.16 & 50 \\
& 20 & Maple Presto & 100.56 & 3.58 & 50 \\
c§ & 1 & BSR 201 & 99.89 & 3.69 & 50 \\
& 2 & Hardee & 99.71 & 2.83 & 50 \\
& 19 & Amsoy & 99.45 & 2.35 & 50 \\
& 20 & Maple Presto & 100.95 & 2.59 & 50 \\
\hline
\end{tabular}

*Rank assignment in Graham et al. (1994).

†Cultivar differences not significant $\left(F_{3,8}=0.2543\right)$. \$Cultivar differences not significant $\left(F_{3,16}=1.4992\right)$; average DNA content is 0.2584 -fold that of Pisum sativum included as standard (five meristems, 10 nuclei each). $\S$ Cultivar differences not significant $\left(F_{3,16}=0.8598\right)$; average DNA content is 0.2554 -fold that of Pisum sativum included as standard (five meristems, 10 nuclei each).

vars was evident (Table 2). The data obtained with both fixatives, methanol-acetic acid and formaldehyde, showed a very similar soybean-pea ratio, demonstrating that both fixatives are adequate in the present measurements. The inclusion of Pisum sativum 'Kleine Rheinländerin' in three of these tests enabled the calculation of an absolute genome size (1C) amounting to $1.133 \mathrm{pg}$, which is 0.2563 -fold that of Pisum sativum (Table 1). This is compatible with the data obtained with EB flow cytometry (1.134 pg, 0.2566-fold that of Pisum sativum). The soybean-pea ratio obtained with DAPI is $0.2974 \pm 0.0037$, which is clearly distorted from the $\mathrm{EB}$ and Feulgen ratios, and may indicate a higher AT content in soybean compared with pea (Table 1).

The genome size data of Graham et al. (1994) and our data obtained with EB, DAPI and Feulgen, and the mean of all three techniques, were analysed for correlation, and in no case was any significance found (Table 1).

\section{Discussion}

The only reasonable conclusions from our data are that the present soybean cultivars are not different in genome size, at least not to an extent that could be demonstrated reliably with our methods, and that there is no correlation with maturity groups. There is no significant correlation between the data obtained with either method and maturity groups, and also the results of the different methods are not significantly correlated with each other, showing that the marginal variation observed is simply methodological noise. It should be stated that the positive correlation between genome size and maturity groups observed by Graham et al. (1994) results from a single exceptionally low value in 'Maple Presto'. If this value is omitted, the significance is lost $[r=0.4296$ and $P=0.066$ for the means in Graham et al. (1994) correlated with their maturity groups; if 'Maple Presto' is included, the means correlate at $P=0.022$ and $r=0.5077$, which is worse than $r=0.55$ found in Graham et al. (1994)]. Furthermore, three of the maturity groups in Graham et al. (1994) differ slightly from the USDA listing (Lohnes \& Bernard, 1991; R. L. Nelson, personal communication). If these assignments are corrected (see Table 1), the significance is further reduced to $P=0.079$ at $r=0.4126$.

\section{Acknowledgements}

We are very grateful to Dr R. L. Nelson, Curator, USDA, Agricultural Research Service, for the soybean cultivars. We also thank Dr J. Vollmann, Institute of Plant Cultivation and Breeding, Agricultural University, Vienna, for soybean samples. We are very indebted to Mag. M. Baranyi for contributing her methodical experience with flow cytometry. Dr J. Doležel made useful suggestions. The work was supported by the Austrian Science Foundation, research grant P09593-BIO.

\section{References}

BARANYI, M. AND GREILHUBER, J. 1995. Flow cytometric analysis of genome size variation in cultivated and wild Pisum sativum (Fabaceae). Pl. Syst. Evol., 194, 231-239.

BARANYI, M. AND GREILHUBER, J. 1996. Flow cytometric and Feulgen densitometric analysis of genome size variation in Pisum. Theor. Appl. Genet., 92, 297-307.

BENNETT, M. D. 1985. Intraspecific variation in DNA amount and the nucleotypic dimension in plant genetics. In: Freeling, M. (ed.) Plant Genetics, UCLA Symposia on Molecular and Cellular Biology, New Series, Vol. 35, pp. 283-302. Alan R. Liss, New York.

BENNETT, M. D. 1987. Variation in genomic form in plants and its ecological implications. New Phytol., 106 (Suppl.), 177-200.

BENNETT, M. D. AND LEITCH, I. J. 1995. Nuclear DNA amounts in angiosperms. Ann. Bot., 76, 113-176. 
DOLEŽEL, J. 1991. Flow cytometric analysis of nuclear DNA content in higher plants. Phytochem. Analyt., 2, 143-154.

DOLEŽEl, J., SGORBATl, S. AND LUCRETTl, S. 1992. Comparison of three DNA fluorochromes for flow cytometric estimation of nuclear DNA content in plants. Physiol. Plant., 85, 625-631.

GRAHAM, M. J., NICKELL, C. D. AND RAYBURN, A. L. 1994. Relationship between genome size and maturity group in soybean. Theor. Appl. Genet., 88, 429-432.

GREllhuBER, J. 1986. Severely distorted Feulgen-DNA amounts in Pinus (Coniferophytina) after nonadditive fixations as a result of meristematic self-tanning with vacuole contents. Can. J. Genet. Cytol., 28, 409-415.

GREILHUBER, J. 1987. 'Self-tanning' - a new and important source of stoichiometric error in cytophotometric determination of nuclear DNA content in plants. Pl. Syst. Evol., 158, 87-96.

GREILHUBER, J. AND EBERT, 1. 1994. Genome size variation in Pisum sativum. Genome, 37, 646-655.

HAMMATT, N. AND BLACKHALL, N. W. AND DAVEY, M. R. 1991. Variation in the DNA content of Glycine species. J. Exp. Bot., 42, 659-665.

KöNIG, C., EBERT, 1. AND GReIlhuber, J. 1987. A DNA cytophotometric and chromosome banding study in Hedera helix (Araliaceae), with reference to differential DNA replication associated with juvenile-adult phase change. Genome, 29, 498-503.

LOHNES, D. G. AND BERNARD, R. L. 1991. Ancestry of US/Canadian commercial cultivars developed by public institutions. Soybean Genet. Newsl., 18, 243-255.

PRICE, H. J. 1988. Nuclear DNA content variation within angiosperm species. Evol. Trends Plants, 2, 53-60.

RAYBURN, A. L. 1990. Genome size variation in Southwestern United States maize adapted to various altitudes. Evol. Trends Plants, 4, 53-57.

RAYBURN, A. L. AND AUGER, J. A. 1990. Genome size variation in Zea mays ssp. mays adapted to different altitudes. Theor. Appl. Genet., 79, 470-474.

RAYBURN, A. L., PRICE, H. J., SMITH, J. D. AND GOLD, J. R. 1985. C-band heterochromatin and DNA content in Zea mays (L.). Am. J. Bot., 72, 1610-1617.

rohlf, F. J. 1992. віом. A Package of Statistical Programs to Accompany the Text 'Biometry'. Applied Biostatistics, New York.

ULRICH, I. AND ULRICH, w. 1986. Flow cytometric DNA analysis of plant protoplasts stained with DAPI. $Z$. Naturforsch., 41c, 1052-1056. 